\title{
PROBLEMS OF AN AERODYNAMIC INTERFERENCE BETWEEN HELICOPTER ROTOR SLIPSTREAM AND AN ELEVATED HELIPORT
}

\author{
Pawel Ruchała, Kamila Grabowska \\ Łukasiewicz Research Network - Institute of Aviation \\ Department of Aerodynamics \\ Krakowska Av. 110/114, 02-256 Warsaw, Poland \\ tel.: +48228460011ext.312 \\ e-mail:pawel.ruchala@ilot.edu.pl,kamila.grabowska@ilot.edu.pl
}

\begin{abstract}
An elevated heliport, as it has been defined by FAA (Federal Aviation Administration), is a heliport located on a rooftop or other elevated structure where the TLOF (touchdown and lift-off area) is at least 30 inches (76 cm) above the surrounding surface [1]. One of greatest advantages of such heliports is that they require less free space, which eases its build nearby existing buildings - especially in densely built-up areas. However, design of such heliports is more complicated, than ground level ones, while one must include an aerodynamic impact of the building below the elevated heliport and surrounding buildings. The aerodynamic interference between the helicopter and the buildings may result with decline of flight safety, due to sudden decrease of thrust (when flying above the edge of building) or because of increased turbulence in windy weather, wake behind surrounding buildings causing sudden gusts etc. Moreover, oscillations of pressure caused by helicopter rotor influence on the building structure also must be taken into account due to increased wear of upper part of the building or devices mounted on its roof (for example, elevator drives). These oscillation may also cause vibrations of building's structure, which is especially important in case of medical heliports - which are a vast majority of elevated heliports (and heliports in general) - because of strict requirements for acceptable vibration level. The article is aimed on summarize aerodynamic issues, which should be taken into account during design of elevated heliport.
\end{abstract}

Keywords: transport, helicopter flight safety, rotor wake, elevated heliport

\section{Introduction}

One of greatest advantage of rotorcrafts, known from its very beginning, was its mobility - due to capability of vertical take-off and landing. In general, this feature gave new possibilities to the air transport, which to that time was tethered to the airports. An exception were STOL (Short Take-Off and Landing) fixed-wing aircrafts, which could land e.g. on a grassland or on a field however its small size was a significant limitation for use them as a transport mean. During Second World War, the helicopter quite rapidly emerged from being an experimental machine that was fundamentally precarious and often downright dangerous to even attempt to fly, to a more stable and airworthy mode of transport [2]. This fact triggered new concepts of use helicopters in modern society. The concept for a high-speed personal helicopter was an early expression of what would become in the years immediately after World War II an extremely popular vision of the future. To many observers, the helicopter seemed to promise wings for the city dwellers who might land atop their apartments or office buildings [3]. In general, helicopters were seen either as a personal transport mean, like a car, travelling between any convenient locations, or as a commuter joining relatively large heliports - similarly to buses, trains or other public transport means. Some other examples, considered in the UK at that time, are described widely in [2].

One of most iconic heliports designed and built at that time, was located on the roof on the 60-storey Pan Am Building in midtown Manhattan (Fig. 1) [4]. The helipad had opened in 1965 and operated shuttle flights to nearby airports, but closed in 1968, as it was unprofitable [4]. 
In May 1977, shortly after its reactivation, the heliport was involved in a tragedy. A failure of the landing gear of Sikorsky S-61L helicopter caused its collapse, due to which one of the rotor blades felt off. As it was described in the New York Times article, (...) whirling like a gigantic boomerang the blade struck four people on the rooftop land pad, killing three instantly, then plunged over the skyscraper's west parapet. ... One piece of blade continued to fall, whirling onto Madison Avenue, and killing a woman walking on Madison and 43rd Street shortly after $5.30 \mathrm{pm}[5]$.
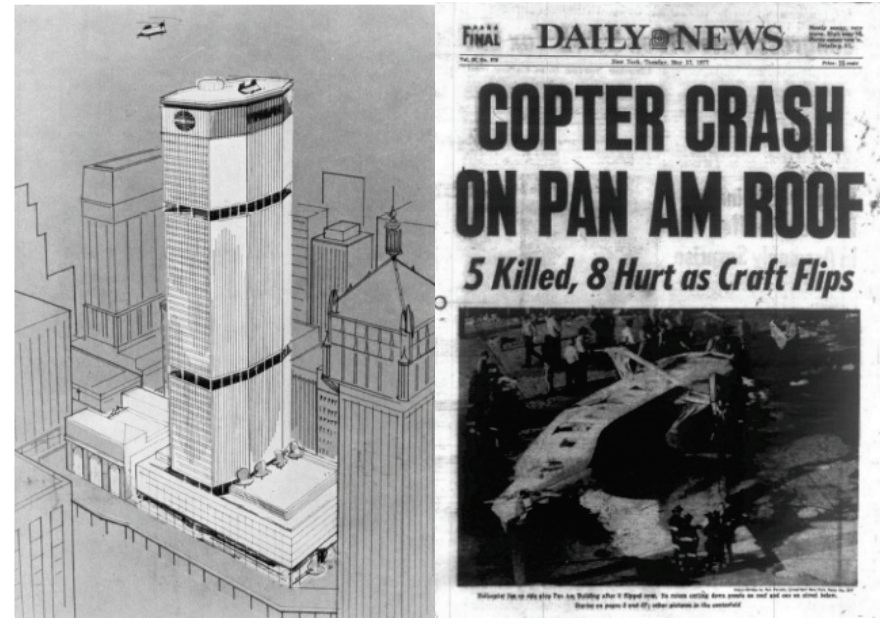

Fig. 1. The Pan Am Building with the heliport on its roof (left) and Sikorsky S-61L crashed on it pictured on Daily News cover [2, 6]

The crash on Pan Am Building indicated clearly that a significant disadvantage of elevated heliports is its safety in case of helicopter failure. It is inherently related with low failure safety of helicopters in general, caused by high amount of kinetic energy of rotor. However, this fact drastically stopped development of heliports located in cities. Another limitation was - and still is - the noise. Helicopter operations are being inhibited or curtailed in North America, Europe and many other parts of the world by objections and concerns about noise [7]. This issue is still valid and needs to be much more examined, while the reaction to helicopters and heliports is dependent on several factors, some of which are completely unrelated to the absolute level of the helicopter noise. These non-acoustic phenomena described collectively as virtual noise are usually triggered by acoustic noise although there is some evidence of a visual trigger [7].

Safety issue and noise annoyance disposed the bulk use of helicopters as a transport mean in dense populated areas (e.g. cities). However, helicopters became irreplaceable in emergency cases - first of all, in life saving. In this case, time needed to transport of a patient to a hospital must be minimized at all costs - but with respective safety. This fact may be observed e.g. in evidence of airports and heliports, by Polish Civil Aviation Authority (Urząd Lotnictwa Cywilnego). Until April 2018, the evidence covered 185 medical heliports (both on ground level and elevated), which makes up $70 \%$ of all heliports.

What must be mentioned, in 2010 started a significant growth of interests in heliports in Poland, mostly medical ones (Fig. 2). It is related with the Ministry of Health decree from 15.03.2007 [8] and its novelization from 3.11.2011 [9]. According to that decree, Emergency Rooms in hospitals should have an access to a heliport, which would enable a transport of patient from a helicopter to the ER without use of dedicated, medical transport means.

Lack of free space in proximity of some hospitals caused that some heliports requested by the decrees of Health Ministry were designed as elevated ones. First of elevated heliports, included in the CAA evidence, was the heliport in the W. Biegański Regional Specialistic Hospital in Grudziadz, built in 2011 [10]. Since that moment, 36 elevated heliports (which give about 14\% of all heliports) have been built and included in the CAA statistics. However, design and built of 


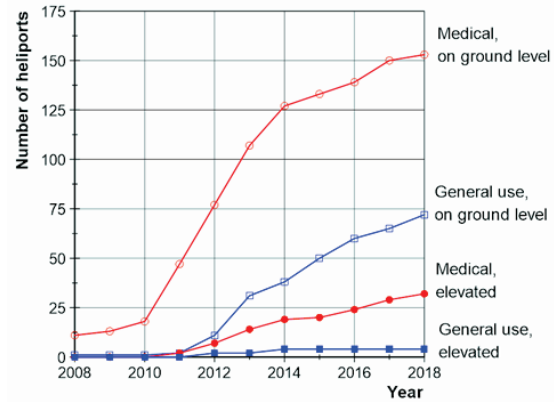

Fig. 2. Number of all heliports included in the airport evidence per year (based on [11])

heliports in Poland still are relatively new branch of engineering. Thus, there is a lack of knowledge, due to which the general safety and utility of hospital buildings with elevated helipad are not sufficiently assured [12]. Shape of the terrain and obstacles surrounding the helicopter deflect the flow around it, sometimes in unpredictable for pilots' manner. That could cause a lot of trouble until specific phenomena is recognized and the pilots learn to avoid certain flight conditions over specific locations [13]. These sentences are valid not only in Poland - over $60 \%$ of helicopter accidents included in the Joint Helicopter Safety Analysis Team (JHSAT) database [14] occur during take-off and landing - i.e. generally in the presence of ground obstacles [15].

\section{Aerodynamic issues related to elevated heliports - previous activities}

The aerodynamic interaction between a helicopter and obstacles (not only elevated heliports) is a quite important research subject and several numerical and experimental studies have been published in the scientific literature [15]. Recently this topic was thoroughly investigated e.g. within GARTEUR Action Group HC/AG-22 project which deals with the basic research about the forces acting on obstacles when immersed in rotor wakes [16]. In this project four research centres: CIRA (I); DLR (D); NLR (NL); ONERA (F); and three universities: NTUA (GR); Politecnico di Milano (I); University of Glasgow (UK) were involved. Safety of helicopter operations on heliports was also investigated in reference to specific heliports, e.g. in USA [17] and in Poland - especially in Institute of Aviation, as a part of activities devoted to improvement of helicopter operation safety $[13,18,19]$. Some helpful information can be also found in the literature, which covers approach and landing of helicopters on ships' helidecks [20-23].

It must be noted that most of papers focused on the aerodynamic interference between a helicopter and an obstacle simplified the rotor wake as a steady one. On the other hand, unsteadiness of the wake in ground effect was thoroughly investigated in works covering the brownout phenomena (which means a dust floating in the air during landing of helicopter), e.g. [24-26]. However, in this case, an aerodynamic loads acting on the ground are neglected researchers were focused on aerodynamic phenomena, which appear in the rotor slipstream.

\section{Ground effect during a hover above a heliport}

During a flight of a helicopter above an elevated heliport, the ground effect phenomenon may appear. In this case, the rotor slipstream bounces from the heliport's surface, which causes an outwash, i.e. a horizontally directed flow outside the helicopter. In the structure of the slipstream of a helicopter rotor in the ground effect (IGE) one can distinguish four regions [26], as it has been presented in Fig. 3:

1. Contraction, where the slipstream velocity is directed more or less vertically - similar to the OGE (out of ground effect) case,

2. Transition, where interaction with the ground turns the flow to the horizontal direction along the ground, 


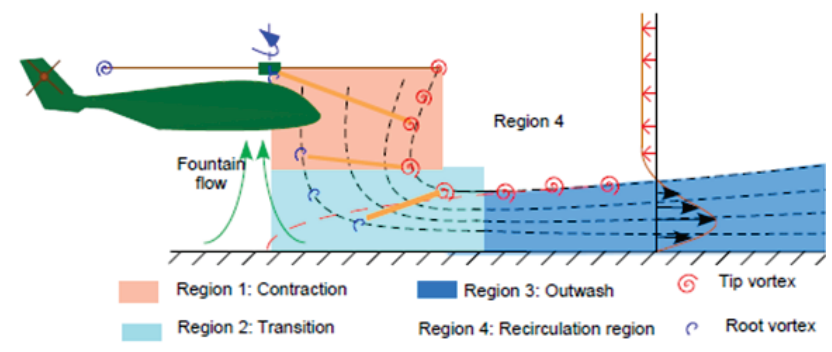

Fig. 3. The slipstream of a helicopter rotor in the ground effect [26]

3. Outwash, where the flow is directed along the ground and its peak value decays with increase in radial distance,

4. Recirculation, where the flow is induced by the slipstream due to air viscosity.

The performance of helicopter in the ground effect is improved in comparison with OGE case. Such improvement usually is described as a ratio of thrust IGE to thrust OGE. This ratio may be given e.g. by Betz equation, which is one of simplest formulae describing thrust increment [27]:

$$
\frac{C_{\text {TIGE }}}{C_{\text {TOGE }}}=\frac{1}{1-\frac{1}{16} \cdot\left(\frac{R}{z}\right)^{2}},
$$

where:

$z$ - height from the ground,

$R$ - rotor radius,

and the thrust coefficient $C_{T}$ is defined with equation:

$$
C_{T}=\frac{T}{\rho \cdot V_{\text {tip }}^{2} \cdot F},
$$

where:

$T$ - thrust force,

$F$ - rotor disc area,

$\rho$ - air density,

$V_{\text {tip }}$ - speed of blade tip.

The slipstream IGE described above is treated as axisymmetric, which is valid for following conditions:

- a horizontal component of air velocity does not appear,

- an unsteadiness of the slipstream is neglected,

- the heliport may be treated as infinitely large (no heliport boundaries are included).

According to [15], thrust increment due to ground effect is nearly the same for flight above an elevated heliport and above ground - as long as whole rotor disk is over the heliport surface (Test 1 and Test 2 in Fig. 4). When the helicopter hovers above an edge of the heliport, the beneficial influence of the ground effect is reduced (Test 3 in Fig. 4). However, the worst case occurs when the helicopter is located next to the building (Test 4 in Fig. 4). In this situation, one can expect even a reduction of thrust to values lower than in OGE case. This effect is caused by vortices created in the edge between the ground and the wall of building, which may encompass the rotor disc (Fig. 5, left). Similar effect appear during the hover above a well-shaped object (Fig. 5, right), but in this case the vortices are roughly axisymmetric. Such structure of the flow is similar to the vortex ring state, with all the consequences [13].

Moreover, even when the helicopter hovers over centre of a helipad, the wake is divided sideways and loses its strength. The flow has tendency for descending down if the nearest roof is lower than the helipad surface, especially when the roof is pitched [13]. It may cause additional wind loads acting on buildings nearby the heliport, which should be taken into account to avoid 
damage of already existing buildings - especially their cladding. The deflected slipstream may also have its impact on the wind comfort of pedestrians and damage loose objects on the sidewalks, for example a furniture.
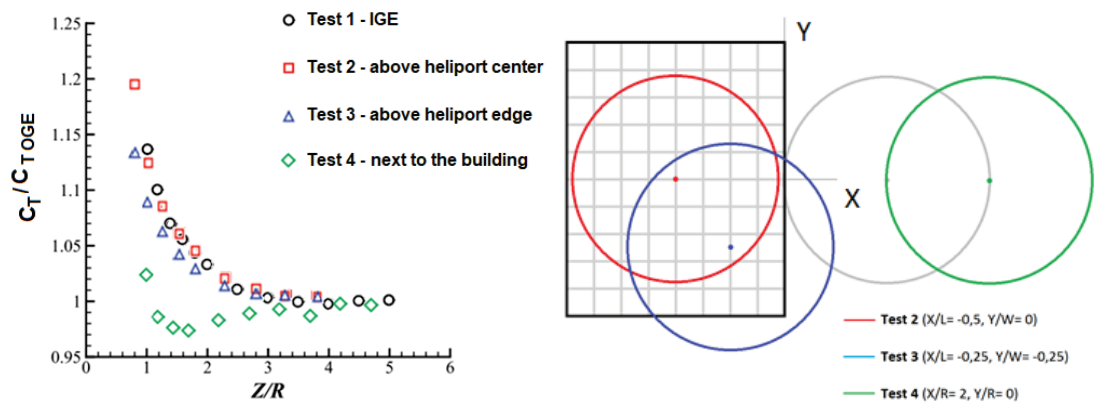

Fig. 4. Left: thrust coefficient (referred to the OGE value) as a function of helicopter vertical location, for different test cases (based on [15]). Right: location of rotor disc versus simulated building in respective test cases (based on [15])

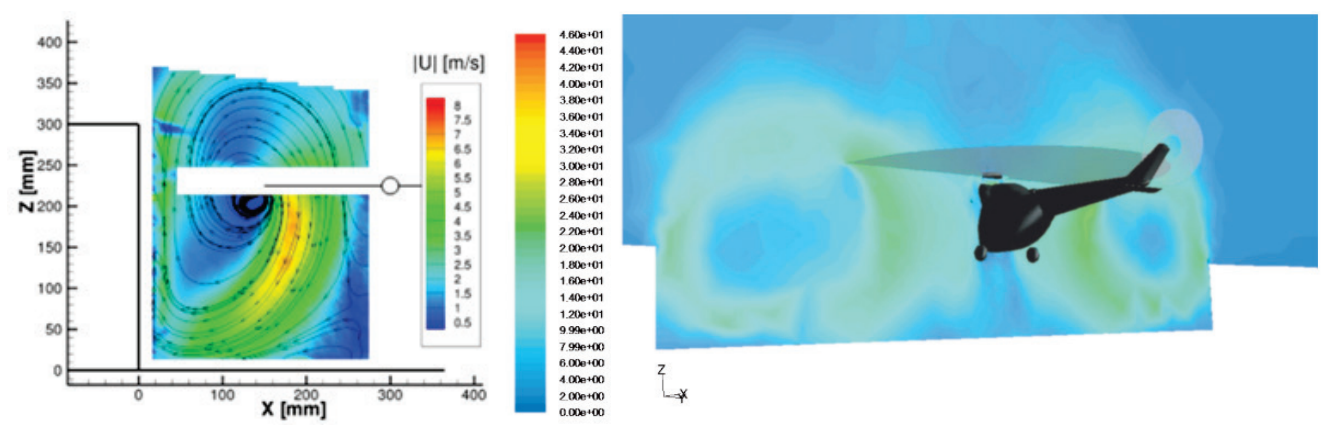

Fig. 5. Left: path lines and flow velocity magnitude for hover next to the wall [15] right: velocity magnitude for hover above a well-shaped terrain [13]

\section{Rotor slipstream in ground effect with an adverse flow}

The previous chapter covered a hover case only. Meanwhile, if horizontal component of air velocity is present, due to the wind or the adverse flight, additional effects of heliport interference should be considered. One of such effects is the ground vortex, created in front of the helicopter. Along a horseshoe-shaped stagnation locus some distance upstream of the rotor, the velocity of the rotor-induced flow moving forward ahead of the helicopter is balanced by the velocity of the free stream [28]. This causes the flow to separate from the ground plane, and the wake of the rotor is observed to roll up to form a concentrated ground vortex just above this separation line [29]. As the wind speed increases, the ground vortex becomes larger and approaches towards the helicopter. For wind, speed of roughly $30 \mathrm{~km} / \mathrm{h}$ the ground vortex encompasses the rotor disc in its front part, which increases required power of $10-20 \%$ more than power required for the hover [30]. Further growth of the wind speed results in a decrease in the power required as the ground vortex is swept downstream of the rotor. At high forward speed, the increased skew-angle of the rotor wake reduces the effectiveness of the ground plane in constraining the geometry of the rotor wake, and the power required by the rotor approaches that required in free air (OGE) [29].

This description of the ground vortex phenomenon is significantly simplified, using the model of two-dimensional, steady flow. In reality, the flow around the rotor is highly unsteady, except well-defined horseshoe-shaped ground vortex. What is more, the inflow has been modelled as uniform, steady flow - which is adequate to the adverse flight. Meanwhile, in case of hover in presence of wind, the inflow is turbulent and non-uniform, as it will be discussed further.

In case of operating from elevated heliport, additional changes are caused by the flow around the building - for example, vertical walls of building below the heliport may deflect the wind 
upwards, which increases a risk of the Vortex Ring State appearance. Secondly, a sharp edge of the building may cause the flow separation above the roof, i.e. in proximity of the TLOF area (Fig. 6). Moreover, the heliport may be located in aerodynamic wake of surrounding buildings, which results with decrease of wind speed and increase its turbulence. As a result, on approach and departure areas, near the helipad, the structures of flow could appear, which are invisible for pilot, but dangerous for a helicopter [19].

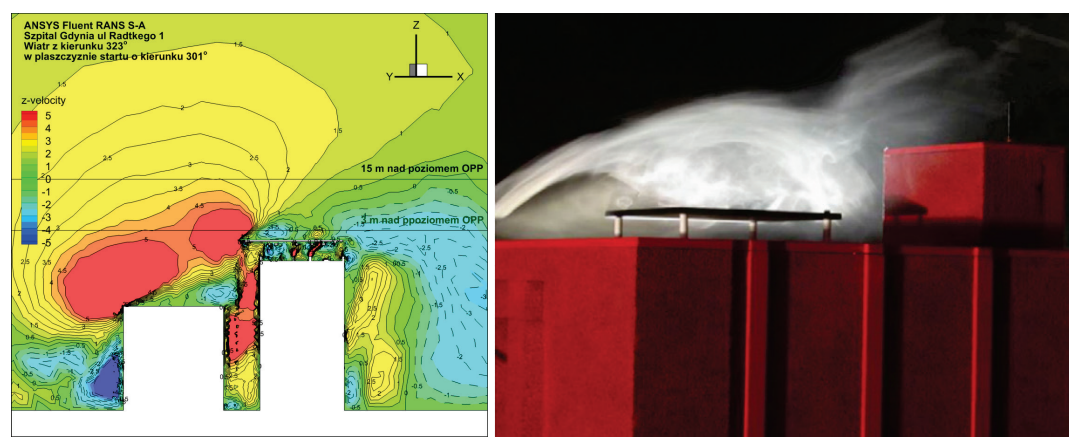

Fig. 6. Left: vertical component of wind velocity around a building; note a dangerous area of upwind on windward (left) side of building [19]. Right: flow separation zone in area of heliport obtained by smoke flow visualization on a wind tunnel model [31]

\section{An unsteadiness of the rotor slipstream}

The phenomena described above assumed that the rotor slipstream is steady, which is a common simplification. In fact, rotor flow is inherently unsteady because of the presence of a finite number of blades. Lifting blades are producing the tip vortices, root vortices, vortex sheets, and oscillations in the inflow (from blade passage). The interaction among these features, as the flow develops, makes the flow field fundamentally unsteady [26]. Moreover, the flow becomes aperiodic because of the self- and mutually induced effects of the strong blade tip vortices [32].

The unsteadiness of slipstream itself becomes even more significant in proximity of ground. In this case, the tip vortices, which flow helically from blade tips, tend to join and grow in the outwash area due to friction. It has been briefly illustrated in Fig. 3. In the boundary layer of the ground, in the outwash zone, a flow separation bubble may also appear. Separation bubbles are created when the static pressure reaches a minimum directly underneath the vortex flow, and then the developing boundary layer faces a steep adverse pressure gradient downstream of the vortex as a consequence of the slower moving fluid and higher pressures there. This pressure gradient can become strong enough to produce localized flow separation and the formation of a separation bubble [25].

It must be underlined that the unsteadiness of slipstream may bring significant problems during operation from elevated heliports, as the oscillating slipstream acts on the heliport plate and causes vibration of building's structure [33]. The unsteadiness of slipstream should be treated, during design of the heliport, as more important than the steady influence of the helicopter on the building, including its weight and time-averaged slipstream [12]. Such vibrations result with increased wear of upper part of the building or devices mounted on its roof. In some cases, the risk of failure of elevator drives is $45 \%$ higher than in a building without heliport [33]. Helicopters create vibration at the landing pad in three ways: (1) turbulence from the rotors, (2) motion from the engine and rotors and (3) impact from the landing itself [31]. The most important reason is the first one, related mostly with helical tip vortices created on the tips of blades. The frequency of these vibrations equals a multiplication of rotor rotation frequency and number of blades [31] thus for commonly used (e.g. in Polish medical service) Eurocopter EC-135 helicopter, frequency of such vibrations will be about $25 \mathrm{~Hz}$. This frequency is in range of frequencies, which should be analysed due to its impact on people and buildings (up to $80 \mathrm{~Hz}$ [34]). 


\section{Conclusion}

Elevated heliports play an important role in helicopter operation, especially in life saving, as they significantly shorten the time of patient's transport from the medical helicopter to the hospital and do not need any free space next to the building. Nevertheless, designers and operators of elevated heliports must be warned about some adverse aerodynamic phenomena, which may appear during approach, take-off or landing of helicopter. One of such phenomena is a steep change of thrust when the helicopter flies above the edge of building on the low altitude; this change is related with sudden change of height above the ground, which affects the ground effect or with air recirculation enforced by the ground and by walls of a building. Secondly, flying in the wake of high building surrounding the heliport is inherently connected with sudden change of wind velocity and air turbulence, which obviously exacerbate the flight safety. Increased turbulence above the heliport may be also caused by the flow separation on the building's edge.

The abovementioned phenomena have their impact on the helicopter and those are caused by its ambience. However, the helicopter also causes some aerodynamic phenomena, which impacts on the heliport or its surrounds. One of such examples, which seem to be underrated, is an unsteadiness of the rotor slipstream, which results with oscillation of static pressure acting on the heliport. Such oscillation, with its frequency of about $25 \mathrm{~Hz}$, may cause vibration of the whole building. This vibration, in turn, may limit a usage of medical equipment, which has strict vibration requirements - the acceptable vibration acceleration is 32 times lower, than in case of offices or apartments. An intensive usage of heliport may also result with increased fatigue of devices located on the building's roof, like lift machinery; the risk of its failure is even $45 \%$ higher.

\section{References}

[1] Federal Aviation Administration, Advisory Circular AC 150/5390-2B: Heliport Design, p. 98, 2006.

[2] Dodge, M., Brook, R., Helicopter dreaming : the unrealised plans for city centre heliports in the post-war period, 2014, available: http://www.bcu.ac.uk/Download/Asset/f196 b9240666-4194-b34c-e2388e71463a.

[3] Corn, J. J., Horrigan, B., Yesterday's tomorrows: past visions of the American future, Baltimore: Johns Hopkins University Press, 1984.

[4] De Voogt, A., Helidrome Architecture, Rotterdam: 010 Publishers, 2007.

[5] 5 killed as copter on Pan Am Building throws rotor blade, The New York Times, 1977.

[6] Copter Crash on Pan Am roof, Daily News, 1977.

[7] Leverton, J. W., Pike, A. C., Helicopter Noise - what is important from a community prospective?, in AHS 63rd Annual Forum Proceedings - AHS International, 2007.

[8] Rozporzadzenie Ministra Zdrowia $z$ dn. 15.03 .2007 w sprawie szpitalnego oddziału ratunkowego, 2007.

[9] Rozporzadzenie Ministra Zdrowia $z$ dn. 3.11.2011 w sprawie szpitalnego oddziału ratunkowego, Poland 2011.

[10] Pierwsze ladowisko wyniesione w Polsce, Urząd Lotnictwa Cywilnego, 2011, online, available: http://ulc.gov.pl/pl/publikacje/wiadomosci/1259-pierwsze-ldowisko-wyniesione-w-polsce.

[11] Ewidencja lądowisk. Urząd Lotnictwa Cywilnego, 2018.

[12] Wąchalski, K., Ocena uwarunkowań konstrukcyjnych wyniesionych lądowisk dla helikopterów na budynkach szpitalnych realizowanych obecnie $w$ Polsce, Transactions of the Institute of Aviation, Vol. 244, No. 3, pp. 179-191, 2016.

[13] Dziubiński, A., CFD analysis of rotor wake influence on rooftop helipad operations safety, Transactions of the Institute of Aviation, Vol. 242, No. 1, pp. 7-22, 2016.

[14] U.S. Joint Helicopter Safety Analysis Team, The Compendium Report: The U.S. JHSAT 
Baseline of Helicopter Accident Analysis Volume I, 2011.

[15] Gibertini, G., Grassi, D., Parolini, C., Zagaglia, D., Zanotti, A., Experimental investigation on the aerodynamic interaction between a helicopter and ground obstacles, Proceedings of the Institution of Mechanical Engineers, Part G: Journal of Aerospace Engineering, Vol. 229, No. 8, pp. 1395-1406, 2015.

[16] Visingardi, A. et al., Forces on Obstacles in Rotor Wake - A GARTEUR Action Group, in 43rd European Rotorcraft Forum, 2017.

[17] Horn, J. F., Keller, J. D., Whitehouse, G. R., Mckillip, R. M., Analysis of Urban Airwake Effects on Heliport Operations At the Chicago Children's Memorial Hospital, 2011.

[18] Łusiak, T., Dziubiński, A., Szumański, K., Interference Between Helicopter and Its Surroundings, Experimental and Numerical Analysis, Task Quarterly, Vol. 13, No. 4, pp. 379-392, 2009.

[19] Dziubiński, A., CFD analysis of wind direction influence on rooftop helipad operations safety, Transactions of the Institute of Aviation, Vol. 242, No. 1, pp. 23-35, 2016.

[20] Crozon, C., Steijl, R., Barakos, G. N., Numerical study of rotors in ship airwake, in 39th European Rotorcraft Forum, 2013.

[21] Lee, R. G., Zan, S. J., Wind tunnel testing of a helicopter fuselage and rotor in a ship airwake, in 29th European Rotorcraft Forum, 2003.

[22] Lee, D., Sezer-Uzol, N., Horn, J. F., Long, L. N., Simulation of Helicopter Shipboard Launch and Recovery with Time-Accurate Airwakes, Journal of Aircraft, Vol. 42, No. 2, pp. 448-461, 2005.

[23] Paquet, J. B., Bourez, J. P., Morgand, S., Formulation of Aerodynamic Forces on Helicopters in Non Uniform Flow with Scale Model Tests: Ground Effects, in 49th International Symposium of Applied Aerodynamics, 2014.

[24] Nathan, N. D., Green, R., Measurements of a rotor flow in ground effect and visualization of the brown-out phenomenon, in 64th Annual Forum of the American Helicopter Society, Montreal, Quebec, 2008.

[25] Johnson, B., Leishman, J. G., Sydney, A., Investigation of Sediment Entrainment Using Dual-Phase, High-Speed Particle Image Velocimetry, Journal of the American Helicopter Society, Vol. 55, No. 4, pp. 42003-1-42003-16, 2010.

[26] Ramasamy, M., Potsdam, M., Yamauchi, G. K., Measurements to Understand the Flow Mechanisms Contributing to Tandem-Rotor Outwash, in 71 American Helicopter Society Forum, Virginia Beach, VA, USA 2015.

[27] Witkowski, R., Budowa i pilotaż śmigłowców, 2nd ed., WKiŁ, Warszawa 1986.

[28] Curtiss, H. C., Erdman, W., Sun, M., Ground Effect Aerodynamics, Vertica, Vol. 11, No. 1/2, pp. 29-42, 1987.

[29] Brown, R. E., Whitehouse, G. R., Modelling rotor wakes in ground effect, Journal of the American Helicopter Society, Vol. 49, No. 3, pp. 238-249, 2004.

[30] Łusiak, T., Analiza numeryczna oraz badania eksperymentalne zjawiska ETL, Mechanika w Lotnictwie ML-XIV, Vol. 2, pp. 525-548, 2010.

[31] Smith, A., Bell, A., Hackett, D., Trade-offs in helipad sitting\&design, Rowan Williams Davies \& Irwin Inc. (RWDI), pp. 1-10, 2017.

[32] Bhagwat, M. J., Leishman, J. G., Stability Analysis of Helicopter Rotor Wakes in Axial Flight, Journal of the American Helicopter Society, Vol. 45, No. 3, pp. 165-178, 2000.

[33] Mejssner, M., Heliports dangerous for structure of buildings, Administrator, 24, 2011.

[34] PN-B-02171 standard, Estimation of impact of vibration on people in buildings, 2017. Manuscript received 17 July 2019; approved for printing 19 September 2019 